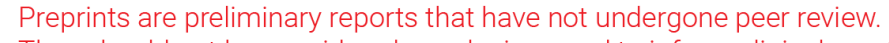 They should not be considered conclusive, used to inform clinical practice, or referenced by the media as validated information. \\ Synergistic PAHs biodegradation by a mixed bacterial community: Based on a multisubstrate enrichment approach
}

\section{Kang Li}

China University of Mining and Technology

\section{Yanzehua Liu}

China University of Mining and Technology

\section{Yangda Li}

China University of Mining and Technology

\section{Dan Li}

China University of Mining and Technology

$\mathrm{Na}$ Liu

China University of Mining and Technology

\section{Liping Wang ( $\nabla$ wlpcumt@126.com )}

China University of Mining and Technology

https://orcid.org/0000-0001-7263-1037

\section{Research Article}

Keywords: Mixed bacterial community, Multisubstrate enrichment, Biodegradation, Pathway intermediate metabolites, Polycyclic aromatic hydrocarbons

Posted Date: November 15th, 2021

DOl: https://doi.org/10.21203/rs.3.rs-973148/v1

License: (9) This work is licensed under a Creative Commons Attribution 4.0 International License. Read Full License 


\section{Abstract}

Polycyclic aromatic hydrocarbons (PAHs) are highly hard-biodegradable compounds. Therefore, in this work, a multisubstrate enrichment approach was proposed to develop a bacterial community named MBF from activated sludge of coking wastewater plant capable of degrading mixed-PAHs consisting of phenanthrene and pyrene ( $50 \mathrm{mg} / \mathrm{L}$ of each) by $98.8 \%$ and $73.3 \%$ within 5 days, respectively. The bacterial community could maintain its degradation ability to mixed PAHs relatively under temperatures $\left(20^{\circ} \mathrm{C}-35^{\circ} \mathrm{C}\right), \mathrm{pH}$ values $(5.0-9.0)$, and salinities $(0-10 \mathrm{~g} / \mathrm{L} \mathrm{NaCl})$. Additionally, the bacterial community MBF degraded $58.9 \%, 79.9 \%$, and $80.7 \%$ of mixed PAHs in the presence of catechol, salicylic acid, and phthalic acid, respectively within 5 days. High-throughput sequencing of 16S rRNA gene amplicon analysis showed that the bacterial community MBF was dominated by Pseudomonas in most treatments, and Burkholderia was predominant under both acidic condition and high salt concentrations. Furthermore, the composition of microbial communities of the bacterial community was significantly different with/without addition of pathway intermediate metabolites after biodegradation of mixed PAHs, revealing the metabolic burden may be distributed between members of this bacterial community. Those results demonstrate that the biodegradation ability of MBF could be maintained with the bacterial community structure altering when facing environmental variations or changes in composition of target contaminants.

\section{Introduction}

Polycyclic aromatic hydrocarbons (PAHs) are organic compounds composed of two or more aromatic rings with different structural configuration (Nzila, 2018). As a kind of typical persistent organic pollutants, PAHs are widely present in environmental media such as soil, sediments and water bodies owing to some natural and human activities, including wildfires, volcanic explosion, oil refining and petrochemical industries (Haritash and Kaushik, 2009). PAHs contamination has raised significant concerns for environmental and human health due to their high toxicity, reluctance to biodegradation and high bioaccumulation (Blumer et al., 1977; Downward et al., 2014). Due to all the above characteristics, 16 kinds of PAHs have been listed as priority pollutans by the USEPA.

Compared to conventional physicochemical approaches, bioremediation referring to the technique that employs microorganism to eliminate pollutants has been proven environmentally sustainable, ecofriendly and economical for PAHs degradation (Gillespie and Philp, 2013; Kumari et al., 2018; Li et al., 2009; Ma et al., 2021). The contaminated environment by PAHs usually contains multiple PAHs and various intermediates produced during the microbial metabolic process of PAHs. Considering many different interactions (e.g., co-metabolism, inhibition, and cross induction) have been identified among PAHs and/or PAHs metabolites, thus it is essential to evaluate the degradation of PAHs in their metabolite mixture for successful remediation (Dean-Ross et al., 2002; Gupta et al., 2015). Furthermore, the overall degradation and removal rate of PAHs are closely related to environmental factors including $\mathrm{pH}$ value, temperature, and salinity. These factors may have an impact on microbial growth, activity and pollutant bioavailability during PAH biodegradation (Patel et al., 2018; Yu et al., 2018). Consequently, it is 
significant to develop a microbial community that can exhibit stable and effective degradability for a mixture of PAHs with their metabolites and under various environmental conditions.

Several studies have shown that mixed bacterial consortia exhibits more effectively than pure bacterial cultures, because there may be multiple degradation pathways, efficient and synergistic metabolic activities (Kumari et al., 2018; Kuppusamy et al., 2016b; Wanapaisan et al., 2018). The defined microbial consortia was constructed for bioprocessing using 'top-down' or 'bottom-up' methods. The 'bottom-up' approach starts to mix two or more isolated and characterized strains as the inoculums to degrade pollutants, and the interaction among these strains may be metabolically engineered. However, microbial consortia constructed by this approach lack stability and metabolic diversity due to inherent limitation by knowledge of characterized strains (Iwabuchi et al., 2002). The 'top-down' approach down-selects stable microbial communities sourced from the natural environment to build consortia which possess remarkable stability and resilience (Gilmore and O'Malley, 2016). The controlled initial microbiome is exposed to multiple selection cycles and/or regimes, which can lead to the microbiome acquiring or optimizing specific functions through adaptation or evolution (Lawson et al., 2019). Several studies reported that an initial microbiome collected from the contaminated environment by PAHs was successively transferred with gradually increase in concentration of target pollutants to obtain an efficient and stable consortium (Lu et al., 2019; Patel et al., 2018, 2012). Despite the high degradability to PAHs, the consortium may lack the ability to efficiently degrade the metabolites produced during the biodegradation of PAHs, and the accumulation of metabolites can inhibit biodegradation process (Meng et al., 2014; Wen et al., 2011). Moreover, it takes a long time to complete the whole enrichment procedure for adaptation of microbiome to target pollutants. To solve these problems, we propose a multisubstrate enrichment approach to obtain a bacterial community with efficient degradation of target pollutants and intermediate metabolites in a short period of time. The opening of target pollutant is the hardest link in the biodegradation process, and it is also a key factor limiting the mineralization effect of pollutants. As the product of forthcoming ring opening, the intermediate metabolites are used as the primary energy and carbon source for the initial microbiota firstly. The intermediate metabolites could induce some enzyme activities (e.g., $\mathrm{C}_{12} \mathrm{O}, \mathrm{C}_{23} \mathrm{O}$ ) of microbiota, therefore reducing the adaptation time of microbiota to the provided carbon source and accelerating their growth (Sei et al., 2004). In the later stage of enrichment, the microbiota was directly exposed to the target pollutant to acclimate the microbiota that can effectively degrade the target pollutant. Preliminary laboratory studies evaluating the potential of a PAHdegrading consortium are indispensable for the successful implementation of biodegradation of PAHs as a remediation technology (Bacosa and Inoue, 2015).

In this current study, the mixed bacterial community MBF was developed from activated sludge of coking wastewater treatment plant (CWWTP) of Huayu Gas (Xuzhou, China) through a multisubstrate enrichment approach, in which catechol, salicylic acid and phthalic acid were selected as pathway intermediate metabolites of PAHs, and phenanthrene and pyrene were target contaminant. Furthermore, the mixture of phenanthrene and pyrene degradation by MBF and its microbial community structure under environmental conditions $(\mathrm{pH}$, temperature and salinity) and in the presence of pathway 
intermediate metabolites (catechol, salicylic acid and phthalic acid) after biodegradation were also investigated.

\section{Materials And Methods}

\subsection{Culture media and chemicals}

Phenanthrene (97\%), pyrene (97\%), salicylic acid (99\%), phthalic acid (99\%) and catechol (99\%) were purchased from Shanghai Macklin Biochemical (Shanghai, China). HPLC grade acetone and methanol were procured from Aladdin Industrial Corporation (Shanghai, China). Minimal salt medium (MSM) used for culture growth and maintenance had (per L) $\mathrm{MgSO}_{4} \cdot 7 \mathrm{H}_{2} \mathrm{O} 0.2 \mathrm{~g}, \mathrm{KH}_{2} \mathrm{PO}_{4} 4.5 \mathrm{~g}, \mathrm{Na}_{2} \mathrm{HPO}_{4} 0.5 \mathrm{~g}, \mathrm{NH}_{4} \mathrm{Cl}$ $2.0 \mathrm{~g}$, and trace element such as $\mathrm{ZnCl}_{2} 0.23 \mathrm{mg}$, $\mathrm{CoCl}_{2} \cdot 6 \mathrm{H}_{2} \mathrm{O} 0.42 \mathrm{mg}, \mathrm{MnSO}_{4} \cdot \mathrm{H}_{2} \mathrm{O} 0.13 \mathrm{mg}$, $\mathrm{Na}_{2} \mathrm{MoO}_{4} \cdot 2 \mathrm{H}_{2} \mathrm{O} 0.15 \mathrm{mg}, \mathrm{AlCl}_{3} \cdot 6 \mathrm{H}_{2} \mathrm{O} 0.05 \mathrm{mg}, \mathrm{CuSO}_{4} \cdot \mathrm{H}_{2} \mathrm{O} 0.03 \mathrm{mg}, \mathrm{CaCl}_{2} 0.01 \mathrm{~g}$ purchased from Nanjing Chemical Reagent (Nanjing, China). Stock solutions of the mixture of phenanthrene and pyrene (each 50 $\mathrm{mg} / \mathrm{L})$ were prepared in acetone.

\subsection{Sampling and multisubstrate enrichment process}

Activated sludge, as the microbial source, was collected from CWWTP of Huayu Gas, located in Xuzhou, Jiangsu Province of China. The wastewater contained a variety of PAHs, thus the microbiota that could degrade PAHs definitely existed in the activated sludge.

The acclimation process of mixed PAH-degrading bacterial ccommunity was based on a multisubstrate enrichment approach, as illustrated in Fig. 1. The specific operation was as follows: activated sludge suspension was diluted with saline, and then aerated in a plastic bucket for $7 \mathrm{~d}$ at $25^{\circ} \mathrm{C}$, and then began the acclimation with addition of pathway intermediate metabolites as primary carbon source. The catechol, salicylic acid and phthalic acid were selected as common pathway intermediate metabolites of PAHs (Patel et al., 2019). The supernatant $(5 \mathrm{~mL})$ was picked out to Erlenmeyer flask ( $250 \mathrm{~mL}$ ) provided with $45 \mathrm{~mL}$ sterilized MSM, $200 \mathrm{mg} / \mathrm{L}$ catechol, and $50 \mathrm{mg} / \mathrm{L}$ of phenanthrene and pyrene (each 25 $\mathrm{mg} / \mathrm{L})$, and incubated for $7 \mathrm{~d}\left(25^{\circ} \mathrm{C}, 150 \mathrm{rpm}\right)$. Successive transfers were performed with gradually increase in concentration ( $200 \mathrm{mg} / \mathrm{L}$ with each transfer after $7 \mathrm{~d}$ incubation) of catechol from $200 \mathrm{mg} / \mathrm{L}$ to $1000 \mathrm{mg} / \mathrm{L}$. Similar acclimation with addition of salicylic acid or phthalic acid were carried out synchronously. After the acclimation with addition of pathway intermediate metabolites, $5 \mathrm{~mL}$ bacterial fluid (15 mL in total) were transferred to $45 \mathrm{~mL}$ sterilized MSM with $100 \mathrm{mg} / \mathrm{L}$ phenanthrene and pyrene (each $50 \mathrm{mg} / \mathrm{L}$ ) as the solo carbon and energy source. With successive transferring that the concentration of phenanthrene and pyrene increased from $100 \mathrm{mg} / \mathrm{L}$ to $400 \mathrm{mg} / \mathrm{L}$ ( $50 \mathrm{mg} / \mathrm{L}$ with each transfer after $7 \mathrm{~d}$ incubation), a mixed $\mathrm{PAH}$-degrading bacterial community was obtained (designated as 'MBF'). The consortium was stored at $4^{\circ} \mathrm{C}$ for further experiments.

\subsection{Effects of initial concentration on PAH degradation}


The degradation experiments were carried out in $50 \mathrm{~mL}$ shaking flask containing $9 \mathrm{~mL} \mathrm{MSM}$ and $1 \mathrm{~mL}$ inoculum provided with a different initial concentration ( $25 \mathrm{mg} / \mathrm{L}, 50 \mathrm{mg} / \mathrm{L}, 100 \mathrm{mg} / \mathrm{L}$ and $200 \mathrm{mg} / \mathrm{L}$ ) of phenanthrene and pyrene separately at $25^{\circ} \mathrm{C}$ under shaking condition $(150 \mathrm{rpm})$. For inoculum preparation, pre-grown MBF was centrifuged at $6000 \mathrm{rpm}$ for $6 \mathrm{~min}$ at $4^{\circ} \mathrm{C}$, washed with fresh $\mathrm{MSM}$ and then re-suspended in fresh MSM. Three replicate flasks were collected at 1, 3 and $5 \mathrm{~d}$ for degradation of phenanthrene and pyrene. Uninoculated flasks containing only MSM supplemented with PAH was used as a control. The biodegradation profiles of phenanthrene and pyrene as a single compound and as a mixture of PAHs were also investigated.

\subsection{Effects of environmental factors on PAHs degradation}

To determine the effects of environmental factors on the degradation of $100 \mathrm{mg} / \mathrm{L}$ of phenanthrene and pyrene (each $50 \mathrm{mg} / \mathrm{L}$ ) by $\mathrm{MBF}$, experiments were performed at different temperature $\left(20^{\circ} \mathrm{C}, 25^{\circ} \mathrm{C}, 28^{\circ} \mathrm{C}\right.$, $30^{\circ} \mathrm{C}$, and $\left.35^{\circ} \mathrm{C}\right), \mathrm{pH}$ value $(5,6,7,8$, and 9$)$ and salinity $(0 \mathrm{~g} / \mathrm{L}, 1 \mathrm{~g} / \mathrm{L}, 3 \mathrm{~g} / \mathrm{L}, 5 \mathrm{~g} / \mathrm{L}$, and $10 \mathrm{~g} / \mathrm{L} \mathrm{NaCl})$. The inoculum process was similar as described in Section 2.3. The phenanthrene and pyrene degradation were monitored on 1st, 3rd and 5th day of incubation. Another three replicate flasks were collected for DNA extraction. Uninoculated flasks containing only MSM supplemented with PAH was used as a control.

\subsection{Effects of pathway intermediate metabolites on PAH degradation}

To investigate the effects of pathway intermediate metabolites on the degradation of $100 \mathrm{mg} / \mathrm{L}$ of phenanthrene and pyrene (each $50 \mathrm{mg} / \mathrm{L}$ ) by MBF, experiments were performed with the supplementation of $0.05 \%(\mathrm{w} / \mathrm{v})$ catechol, phthalic acid or salicylic acid. The inoculum process and incubation conditions were similar as described in Section 2.3. In addition, three replicate flasks were collected for DNA extraction. The flasks without addition of pathway intermediates were kept under similar conditions and served as a control.

\subsection{DNA extraction and bacterial community structure analysis}

Total genomic DNA was extracted from original activated sludge and the consortium using the Mobio PowerSoil $₫$ DNA isolation kit (Qiagen, Shanghai, China) according to manufacturer's instruction. DNA samples in all treatments were extracted in triplicate and combined for further analysis. The V3-V4 variable region of the $16 \mathrm{~S}$ rRNA genes was amplified using forward primer $338 \mathrm{~F}$ and reverse primer $806 \mathrm{R}$ (Liu et al., 2021). The PCR were performed using the following protocol: $3 \mathrm{~min}$ of denaturation at $95^{\circ} \mathrm{C}, 30$ s at $95^{\circ} \mathrm{C}, 30 \mathrm{~s}$ at $55^{\circ} \mathrm{C}, 45 \mathrm{~s}$ at $72^{\circ} \mathrm{C}$, and 27 cycles, a final extension at $72^{\circ} \mathrm{C}$ for $10 \mathrm{~min}$. The PCR productions were further purified using $2 \%$ agarose gel and AxyPrep DNA Gel Extraction Kit (Axygen Biosciences, Union City, CA, USA). Purified Amplicons were sequenced in a paired end format using the Illumine MiSeq PE300 platform by Majorbio BioPharm Technology Co, Ltd (Shanghai, China).

Raw sequences were demultiplexed and quality-filtered using Quantitative Insights Into Microbial Ecology (QIIME, version 1.9.1) with the following instructions: (1) the reads with average quality score $<20$ over a 
50 bp sliding window were truncated; (2) exact barcode matching, two nucleotide mismatch in primer matching, reads containing ambiguous characters were removed; and (3) only sequences that overlapped longer than $10 \mathrm{bp}$ were assembled according to the overlap sequences. After trimming, sequences with at least $97 \%$ identified were defined as an operational taxonomic unit (OTU) using UPARSE (Edgar, 2013). The RDP Classifier was used to assign the taxonomy of each OUT against the Silva 16S rRNA gene database (Quast et al., 2012). The raw data of fungal sequences was deposited in the Sequence Read Archive of NCBI database (PRJNA746429).

\subsection{Determination of PAHs}

The entire content of flash $(10 \mathrm{~mL})$ was added with $20 \mathrm{~mL}$ of methanol using the ultrasonic dissolution promotion to extract the residual phenanthrene and pyrene (Gu et al., 2015). After filtration through 0.22 $\mu \mathrm{m}$ polytetrafluoroethylene membrane, the residual phenanthrene and pyrene in the mixed solution were determined in Flexar Quaternary LC Pump Platform (Flexar LC, PerkinElmer, Singapore) fitted with a C18 column (Brownlee C18, $5 \mu \mathrm{m}, 150 \times 4$.6, PerkinElmer) and a UV/Vis detector. Phenanthrene and pyrene were eluted with a mobile phase (methanol: water, 80:20) at a flow rate of $1 \mathrm{~mL} / \mathrm{min}$ and monitored at $254 \mathrm{~nm}$. The column temperature was $30^{\circ} \mathrm{C}$, and the injection volume was $50 \mu \mathrm{L}$. The chromatograms were recorded and integrated with system software (Chromera 2.1, PerkinElmer).

\subsection{Statistical analysis}

All experiments were carried out in triplicate, and the values of degradation ratio were performed as the mean \pm standard deviation (SD) which was represented in the error bar to show variation within the same experiments. The statistical analyses were carried out on IBM SPSS Statistics 25 . The differences between different samples were analyzed using one-way analysis of variance (ANOVA) test followed by Duncan's multiple range test. P-values $\leq 0.05$ were considered to be significant.

\section{Results And Discussion}

\subsection{Dynamics of the bacterial community during the multisubstrate enrichment process}

The bacterial communities in activated sludge and consortium during the multisubstrate enrichment process were characterized using high-throughput sequencing of 16S rRNA gene amplicons, seen in Fig. 2. Species richness and diversity index were obtained (Table S1). It can be concluded from the Shannon and Simpson indices that the bacterial community of each samples varied and the bacterial diversity became lower as the multisubstrate enrichment proceeded. For the complete dataset, the most abundant phylum was Proteobacteria (91.6-98.8\%) in all samples followed by Actinobacteria (0.9$5.6 \%$ ). Various studies have implicated that higher relative abundance of Proteobacteria and Actinobacteria and their positive correlation in PAHs degradation in PAH-contaminated sites (Chen et al., 2017; Lee et al., 2018; Sharma et al., 2016). 
In addition, the difference and species richness of top 15 dominant genera in all samples during the multisubstrate enrichment process was reflected using a heat map (Fig. S1). The dominant genus was Pseudomonas in original sample AS, but became Ralstonia, Delftia, and Achromobacter in sample CA, SA, and PA, respectively. Ralstonia (Di Gioia et al., 2002) and Achromobacter (Pradeep et al., 2015) have been reported as showing the ability of degrading catechol and phthalic acid, respectively, and Delftia have not previously been reported with biodegradation of salicylic acid. The contribution of the other genera with increasing percentages associated with PAHs biodegradation are supported by previous studies for Stenotrophomonas (Zang et al., 2020), Pseudacidovorax (Dealtry et al., 2018), Novosphingobium (Fida et al., 2017), Enterobacter (Lors et al., 2012), Comamonas (Qin et al., 2019), Chryseobacterium (Xiao et al., 2019), and Burkholderia (Morya et al., 2020). After the acclimation that phenanthrene and pyrene were added as carbon source, the dominant genus was Pseudomonas again in sample MBF. This may due to that Pseudomonas has been considered to be one of the most frequently isolated genera in PAHs biodegradation (Nie et al., 2010).

\subsection{Biodegradation of individual PAH vs mixture of PAHs under different initial concentration}

Figure 3 illustrates phenanthrene and pyrene degradation by MBF when they were provided as individual PAH and as mixed-PAHs under different initial concentration $(25 \mathrm{mg} / \mathrm{L}, 50 \mathrm{mg} / \mathrm{L}, 100 \mathrm{mg} / \mathrm{L}$, and 200 $\mathrm{mg} / \mathrm{L}$ ). When the initial concentration of phenanthrene and pyrene was $25 \mathrm{mg} / \mathrm{L}$ or $50 \mathrm{mg} / \mathrm{L}$, the degradation ratio of phenanthrene was almost $100.0 \%$, both in its presence alone and as a mixture with pyrene. Degradation of pyrene were $99.0 \%$ and $73.3 \%$, respectively, when provided in the mixture, as compared to $73.1 \%$ and $66.3 \%$, respectively, when supplemented as individual PAH. When the initial concentration was $100 \mathrm{mg} / \mathrm{L}$ or $200 \mathrm{mg} / \mathrm{L}$, degradation ratio of individual PAH was rapid as compared to the degradation of individual PAH in the mixture. Reason of these results was that, the cross acclimation and co-metabolism may enhance the biodegradation of PAHs under lower initial concentration of mixed PAHs, and the competitive inhibition and reflection of increased levels of toxicity were revealed under higher initial concentration of mixed PAHs (Couling et al., 2010; Yuan et al., 2002). Besides, phenanthrene was quickly degraded followed by pyrene in above four initial concentrations. It was consistent with previous studies in which the degradation ratios generally increased with decreasing molecular weight (Wu et al., 2013).

\subsection{Effect of environmental factors on PAHs degradation}

The PAHs biodegradation processes are affected by environmental factors such as temperature, $\mathrm{pH}$, and salinity, and these factors may determine the effectiveness of bioremediation (Ghosal et al., 2016). To evaluate the potential degradation capacity of MBF for mixed-PAH, a range of degradation tests were conducted at various temperatures, $\mathrm{pH}$ values, and salinities.

Temperature, as an important factor during the bioremediation of PAHs, has an impact on the microbial metabolism as well as solubility of PAHs (Bandowe et al., 2014; Vidonish et al., 2016). Fig. 4a 
demonstrated that MBF exhibited good biodegradation efficiency between $25^{\circ} \mathrm{C}$ and $35^{\circ} \mathrm{C}$. One-way ANOVA analyses implicated that there had no significant difference for phenanthrene degradation under various temperatures except $20^{\circ} \mathrm{C}$, and for pyrene degradation except $20^{\circ} \mathrm{C}$ and $25^{\circ} \mathrm{C}$ within $5 \mathrm{~d}$. Generally, microbial activities increase with increasing temperature in the appropriate range, due to its enhancement to enzymatic activity and microbial metabolism, which will facilitate the degradation efficiency of PAHs (Liu et al., 2017). On the other hand, with temperature increasing, the dissolved oxygen becomes lower that may reduce the metabolic activity of aerobic microorganisms (Ghosal et al., 2016). Though the enrichment of MBF was carried out at $25^{\circ} \mathrm{C}$, the results of this study showed it had good adaptability to temperature changes.

Generally, most heterotrophic bacteria prefer a neutral to alkaline $\mathrm{pH}$ for their metabolic activity (AlHawash et al., 2018). In this study, no significant difference for phenanthrene and pyrene degradation was observed under $\mathrm{pH}$ values ranging from 5.0 to 8.0 at day 5 , and the degradation rate of phenanthrene still remained $>70 \%$ at $\mathrm{pH}$ value of 9.0 , suggesting the practical implementation of MBF at large scale (Fig. 4b). In fact, the cell permeability barrier may be disrupted under acidic conditions, resulting in a increase of the substrate concentration in the cytosol (Y. H. Kim et al., 2005). The remarkable decrease in $\mathrm{PAH}$-biodegradation at higher $\mathrm{pH}$ value could be attributed to the inhibition to bacterial growth under alkaline environment (Tao et al., 2007). According to Sihag Pathak and Jaroli (2014), the PAH biodegradation efficiency could be maximized under the optimal $\mathrm{pH}$ conditions of $6.5-8$, and this is because a neutral to nearly alkaline environment is suitable for the carboxylation reaction.

Effect of salinity conditions on PAH-biodegradation was presented in Fig. 4c. After 5 days of incubation, MBF were able to degrade phenanthrene $>90 \%$ and pyrene $>60 \%$ under $\mathrm{NaCl}$ concentrations of $0 \mathrm{~g} / \mathrm{L}$ to 3 $\mathrm{g} / \mathrm{L}$, indicating its tolerance to a degree of salinity conditions. When the $\mathrm{NaCl}$ concentration increased to $10 \mathrm{~g} / \mathrm{L}$, the degradation rates significantly decreased to $<40 \%$ and $<20 \%$, corresponding to phenanthrene and pyrene, respectively. These results agreed with previous study in which higher salinity level could causes higher osmotic pressure and lower dissolved oxygen in the medium, thus retarding the enzyme synthesis, bacterial growth, and PAHs biodegradation (Imron and Titah, 2018).

\subsection{Effect of environmental factors on community structure of the consortium MBF during mixed-PAH degradation}

Under different temperatures, the dominated genus of bacterial communities in all treatment after mixedPAH degradation was Pseudomonas, and no obvious effect of temperature on bacterial communities in consortium MBF was observed (Fig. 5a). Genus Pseudomonas are well known degraders of PAHs and has been widely applied to PAHs remediation (Khan et al., 2014; Rabodonirina et al., 2019; Wang et al., 2020). Ma et al. (2012) isolated Pseudomonas sp. JM2 from active sewage sludge of chemical plant and found that it could degrade $>40 \%$ of the mixture of fluorene and phenanthrene $(50 \mathrm{mg} / \mathrm{L})$ in 4 days at $37^{\circ} \mathrm{C}$, and also could up to $24 \%$ of fluorene and $12 \%$ phenanthrene when temperature was $4^{\circ} \mathrm{C}$.

Under different incubation $\mathrm{pH}$, the bacterial compositions in all treatments after mixed-PAH degradation were dominated by Pseudomonas, Burkholderia, Chryseobacterium, and Stenotrophomonas (Fig. 5b). 
Kuppusamy et al. (2016a) isolated two strain Pseudomonas (MTS-1) and Stenotrophomonas (MTS-2) from contaminated site soils and reported that the Pseudomonas (MTS-1) was able to degrade more than $85 \%$ of pyrene $(150 \mathrm{mg} / \mathrm{L})$ at pH 5-8 after 30 days, and the Stenotrophomonas (MTS-2) could remove more than $90 \%$ of pyrene $(150 \mathrm{mg} / \mathrm{L})$ at pH 5-7 after 30 days. The proportions of Burkholderia remarkably increased at $\mathrm{pH} 5,6$ and 9 which may due to its adaptability to a wide range of acidic and alkaline conditions (Morya et al., 2020; Somtrakoon et al., 2008). Report has been implied that Chryseobacterium could degrade all kinds of PAHs such as naphthalene, acenaphthene, phenanthrene (Oberoi et al., 2015).

The bacterial communities in MBF after mixed-PAH biodegradation were affected with addition of $\mathrm{NaCl}$, as shown in Fig. 5c. The proportion of Burkholderia and Novosphingobium significantly increased with the concentration of $\mathrm{NaCl}$ increasing. There have been reports that $0.5-3 \% \mathrm{NaCl}$ was found to be optimal for cell growth of some Burkholderia strains and phenanthrene removal (Liu et al., 2019; Lu et al., 2012). Yuan et al. (2015) analyzed the diversity of bacteria associated with degradation of PAHs in sea water, and the results indicated that bacteria intimately accessorial with Novosphingobium existed in different bacterial consortia.

Additionally, a principal coordinate analysis (PCOA) based on weighted UniFrac dissimilarity was used to compare the bacterial diversity among all samples (Fig. $5 \mathrm{~d}$ ). About $87.2 \%$ of bacterial community variance can be explained from the first two principal components. The initial communities (MBF) and the communities in $\mathrm{T}$ treatments, $\mathrm{pH}$ treatments $(\mathrm{pH}=7$ and $\mathrm{pH}=6)$, and salinity treatments $\left(\mathrm{NaCl} \_5\right.$ and $\mathrm{NaCl} \_10$ ) clustered in the left bottom quadrant. In addition, the communities in T treatments showed least variation over temperature. Among $\mathrm{pH}$ treatments, the communities in acid group $(\mathrm{pH}=5$ and $\mathrm{pH}=6)$ were clearly distinguished from the initial communities (MBF) along the first principal coordinate, while the separation between alkaline group $(\mathrm{pH}=8$ and $\mathrm{pH}=9)$ and MBF was seen along the second principal coordinate. The $\mathrm{NaCl}_{-} 10$ treatment exhibited the most variation in community composition among salinity treatments. The results above demonstrated that MBF showed a response in community composition to environment condition changes. It is worthy noticed that more than $90 \%$ of phenanthrene and $65 \%$ of pyrene were removal at $\mathrm{pH} 5$, indicating that MBF was able to obtain good biodegradation of PAHs under a wide range of environmental conditions by changing the interaction among members of MBF.

\subsection{Effect of pathway intermediate metabolites on mixed- PAH degradation by consortium MBF}

Figure 6 depicts the effect of chose pathway intermediate metabolites on phenanthrene and pyrene degradation by MBF. After incubation of $5 \mathrm{~d}$, degradation of phenanthrene and pyrene was decreased from $93.8-64.6 \%, 91.7 \%$, and $89.6 \%$, and from $72.2-53.5 \%, 68.1 \%$, and $71.8 \%$, respectively, in presence of $\mathrm{CA}, \mathrm{SA}$, and PA. It was worth noting that the initial rate of phenanthrene and pyrene were slowed down significantly, and, nevertheless, it became less distinct with $5 \mathrm{~d}$. This may be due to that the pathway intermediate metabolites were preferentially utilized as carbon source because of their simpler structure, 
resulting in the reduction of phenanthrene and pyrene biodegradation (Huang et al., 2011). In addition, the structural similarity between pathway intermediate metabolites and target contaminant and broad substrate specificity of enzymes lead to a wide range of catabolic activity of PAHs degraders (J. D. Kim et al., 2005). Under multi-component contaminated substrate conditions, some key enzymes induced by easily degradable contaminants would promote the simultaneous metabolism of the refractory contaminants by microorganisms (Gupta et al., 2015).

\subsection{Effect of pathway intermediates on community structure of the consortium MBF after mixed-PAH degradation}

At genus level, obvious changes in composition of microbial communities were observed between adding and non-adding pathway intermediate metabolites samples and demonstrated in Fig. 7. The relative abundance of Pseudomonas in CK sample increased after PAHs biodegradation, while reduced in SA, PA, and CA sample. Additionally, the composition of microbial communities was significantly different among the treatments with pathway intermediate metabolites adding. The dominant bacterial genera in SA sample were Delftia (37.4\%), Curvibacter (14.7\%), Chryseobacterium (13.6\%), and Comamonas (12.7\%), respectively. In PA sample, the dominant bacterial genera were Achromobacter $(27.2 \%)$, Pseudacidovorax (26.6\%), Novosphingobium (17.3\%), Delftia (12.3\%), and Burkholderia (9.1\%). In CA sample, Ralstonia (60.1\%), Comamonas (14.5\%), and Burkholderia (7.3\%) were dominant. The cluster analysis was further conducted to better understand the microbial response in PAHs biodegradation with addition of pathway intermediate metabolites. The cluster plot showed that the control sample without adding pathway intermediate metabolites was clustered with MBF. The bacterial communities of the CA and PA samples were more closely linked and were clustered into one group, and the SA sample was not closely linked to either group.

By analyzing the changes in microbial community composition in the multisubstrate enrichment process (Fig. S1) and the experiment of biodegradation of phenanthrene and pyrene as a mixture in the presence of pathway intermediate metabolites (Fig. 7), we could find that the dominant bacterial genera were similar. This indicated that the addition of pathway intermediate metabolites changed microbial community composition, which may due to the multisubstrate enrichment approach used in our study. In the enrichment, the percentage of dominant genera (Delftia, Achromobacter, Ralstonia) in the process of pathway intermediate metabolites adding were finally less than $10 \%$ after the whole complete enrichment (Fig. S1). However, the proportion of the three dominant genera increased after biodegradation of phenanthrene and pyrene as a mixture in the presence of pathway intermediate metabolites (Fig. 7). These results revealed that the metabolic burden could be distributed between members of MBF. At first glance, during this multisubstrate enrichment process, the members behaved significantly different under stresses of different pathway intermediate metabolites. Besides, different member dominated in differing degrading process. While our study did not provide direct evidence of potential functions for different 
bacteria taxa, nevertheless it could provide useful information in developing strategies to boost bioremediation performance of PAHs.

\section{Conclusion}

In this study, we put forward an approach of multisubstrate enrichment to develop a bacterial community named MBF from activated sludge of coking wastewater plant. This bacterial community exhibited a relatively good capacity to degrade the mixture of phenanthrene and pyrene under temperatures $\left(20^{\circ} \mathrm{C}-\right.$ $\left.35^{\circ} \mathrm{C}\right), \mathrm{pH}$ values $(5.0-9.0)$, and salinities $(0-10 \mathrm{~g} / \mathrm{L} \mathrm{NaCl})$, indicating its excellent resistibility to different environmental stress. The consortium MBF was dominated by Pseudomonas in all environmental conditions after biodegradation of mixed PAHs. Burkholderia was found to be the major genus under both acidic environment and high salt concentrations. Additionally, phenanthrene and pyrene were degraded along with pathway intermediate metabolites like catechol, salicylic acid, and phthalic acid demonstrating the high competency of MBF. The community structure in MBF obviously changed with the addition of pathway intermediate metabolites, implying the metabolic burden could be distributed between members of MBF. Thus, the study provides valuable information that can lead to designing an effective strategy for bioremediation of PAHs contaminated environments.

\section{Declarations}

\section{Availability of data and material}

Original data are available from the corresponding author on reasonable request.

\section{Funding}

This research was financially supported by the National Natural Science Foundation of China (No. 51974314, No. 51778612).

\section{Author information}

Affiliations

School of Environment Science and Spatial Informatics, China University of Mining and Technology, University Road No.1, Xuzhou, 221116, China.

Kang Li, Yanzehua Liu, Yangda Li, Dan Li, Na Liu \& Liping Wang.

Contributions

All the authors contributed to the study conception and design. Liping Wang was responsible for this conceptualization. The experimental equipment and scheme were designed by Li et al. The experiment 
was performed by Kang Li, Yanzehua liu, Dan Li, Yangda Li and Na Liu. Data analysis was performed by Kang Li. The manuscipt was written by Kang Li and Liping Wang.

Corresponding author

Correspondence to Liping Wang

\section{Ethics declarations}

Ethical approval

Not applicable

Consent to participate

Not applicable

Consent to publish

Not applicable

Conpeting interests

The authors declare no competing interests.

\section{References}

Al-Hawash, A.B., Dragh, M.A., Li, S., Alhujaily, A., Abbood, H.A., Zhang, X., Ma, F., 2018. Principles of microbial degradation of petroleum hydrocarbons in the environment. Egypt. J. Aquat. Res. https://doi.org/10.1016/j.ejar.2018.06.001

Bacosa, H.P., Inoue, C., 2015. Polycyclic aromatic hydrocarbons (PAHs) biodegradation potential and diversity of microbial consortia enriched from tsunami sediments in Miyagi, Japan. J. Hazard. Mater. 283, 689-697. https://doi.org/10.1016/j.jhazmat.2014.09.068

Bandowe, B.A.M., Bigalke, M., Boamah, L., Nyarko, E., Saalia, F.K., Wilcke, W., 2014. Polycyclic aromatic compounds (PAHs and oxygenated PAHs) and trace metals in fish species from Ghana (West Africa): Bioaccumulation and health risk assessment. Environ. Int. 65, 135-146.

https://doi.org/10.1016/j.envint.2013.12.018

Blumer, M., Blumer, W., Reich, T., 1977. Polycyclic aromatic hydrocarbons in soils of a mountain valley: Correlation with highway traffic and cancer Incidence. Environ. Sci. Technol. 11, 1082-1084. https://doi.org/10.1021/es60135a002 
Chen, B., He, R., Yuan, K., Chen, E., Lin, Lan, Chen, X., Sha, S., Zhong, J., Lin, Li, Yang, L., Yang, Y., Wang, X., Zou, S., Luan, T., 2017. Polycyclic aromatic hydrocarbons (PAHs) enriching antibiotic resistance genes (ARGs) in the soils. Environ. Pollut. 220, 1005-1013. https://doi.org/10.1016/j.envpol.2016.11.047

Couling, N.R., Towell, M.G., Semple, K.T., 2010. Biodegradation of PAHs in soil: Influence of chemical structure, concentration and multiple amendment. Environ. Pollut. 158, 3411-3420.

https://doi.org/10.1016/j.envpol.2010.07.034

Dealtry, S., Ghizelini, A.M., Mendonça-Hagler, L.C.S., Chaloub, R.M., Reinert, F., Campos, T.M.P. d., Gomes, N.C.M., Smalla, K., 2018. Petroleum contamination and bioaugmentation in bacterial rhizosphere communities from Avicennia schaueriana. Brazilian J. Microbiol. 49, 7266-7271.

https://doi.org/10.1016/j.bjm.2018.02.012

Dean-Ross, D., Moody, J., Cerniglia, C.E., 2002. Utilization of mixtures of polycyclic aromatic hydrocarbons by bacteria isolated from contaminated sediment. FEMS Microbiol. Ecol. 41, 1-7.

https://doi.org/10.1016/S0168-6496(02)00198-8

Di Gioia, D., Barberio, C., Spagnesi, S., Marchetti, L., Fava, F., 2002. Characterization of four olive-millwastewater indigenous bacterial strains capable of aerobically degrading hydroxylated and methoxylated monocyclic aromatic compounds. Arch. Microbiol. 178, 208-217. https://doi.org/10.1007/s00203-0020445-z

Downward, G.S., Hu, W., Rothman, N., Reiss, B., Wu, G., Wei, F., Chapman, R.S., Portengen, L., Qing, L., Vermeulen, R., 2014. Polycyclic aromatic hydrocarbon exposure in household air pollution from solid fuel combustion among the female population of Xuanwei and Fuyuan counties, China. Environ. Sci. Technol. 48, 14632-14641. https://doi.org/10.1021/es504102z

Edgar, R.C., 2013. UPARSE: Highly accurate OTU sequences from microbial amplicon reads. Nat. Methods. https://doi.org/10.1038/nmeth.2604

Fida, T.T., Moreno-Forero, S.K., Breugelmans, P., Heipieper, H.J., Röling, W.F.M., Springael, D., 2017. Physiological and transcriptome response of the polycyclic aromatic hydrocarbon degrading Novosphingobium sp. LH128 after inoculation in soil. Environ. Sci. Technol. 51, 1570-1579. https://doi.org/10.1021/acs.est.6b03822

Ghosal, D., Ghosh, S., Dutta, T.K., Ahn, Y., 2016. Current state of knowledge in microbial degradation of polycyclic aromatic hydrocarbons (PAHs): A review. Front. Microbiol. 7. https://doi.org/10.3389/fmicb.2016.01369

Gillespie, I.M.M., Philp, J.C., 2013. Bioremediation, an environmental remediation technology for the bioeconomy. Trends Biotechnol. 31, 329-332. https://doi.org/10.1016/j.tibtech.2013.01.015 
Gilmore, S.P., O'Malley, M.A., 2016. Microbial communities for bioprocessing: lessons learned from nature. Curr. Opin. Chem. Eng. 14, 103-109. https://doi.org/10.1016/j.coche.2016.09.003

Gu, H., Luo, X., Wang, H., Wu, L., Wu, J., Xu, J., 2015. The characteristics of phenanthrene biosorption by chemically modified biomass of Phanerochaete chrysosporium. Environ. Sci. Pollut. Res. 22, 1185011861. https://doi.org/10.1007/s11356-015-4451-5

Gupta, S., Pathak, B., Fulekar, M.H., 2015. Molecular approaches for biodegradation of polycyclic aromatic hydrocarbon compounds: a review. Rev. Environ. Sci. Biotechnol. 14, 241-269. https://doi.org/10.1007/s11157-014-9353-3

Haritash, A.K., Kaushik, C.P., 2009. Biodegradation aspects of polycyclic aromatic hydrocarbons (PAHs): A review. J. Hazard. Mater. 169, 1-15. https://doi.org/10.1016/j.jhazmat.2009.03.137

Huang, L., Gan, L., Zhao, Q., Logan, B.E., Lu, H., Chen, G., 2011. Degradation of pentachlorophenol with the presence of fermentable and non-fermentable co-substrates in a microbial fuel cell. Bioresour. Technol. 102, 8762-8768. https://doi.org/10.1016/j.biortech.2011.07.063

Imron, M.F., Titah, H.S., 2018. Optimization of diesel biodegradation by vibrio alginolyticus using BoxBehnken design. Environ. Eng. Res. 23. https://doi.org/10.4491/eer.2018.015

Iwabuchi, N., Sunairi, M., Urai, M., Itoh, C., Anzai, H., Nakajima, M., Harayama, S., 2002. Extracellular polysaccharides of Rhodococcus rhodochrous S-2 stimulate the degradation of aromatic components in crude oil by indigenous marine bacteria. Appl. Environ. Microbiol. 68, 2337-2343.

https://doi.org/10.1128/AEM.68.5.2337-2343.2002

Khan, Z., Roman, D., Kintz, T., Delas Alas, M., Yap, R., Doty, S., 2014. Degradation, phytoprotection and phytoremediation of phenanthrene by endophyte Pseudomonas putida, PD1. Environ. Sci. Technol. 48, 12221-12228. https://doi.org/10.1021/es503880t

Kim, J.D., Shim, S.H., Lee, C.G., 2005. Degradation of phenanthrene by bacterial strains isolated from soil in oil refinery fields in Korea. J. Microbiol. Biotechnol. 15, 337-345.

Kim, Y.H., Freeman, J.P., Moody, J.D., Engesser, K.H., Cerniglia, C.E., 2005. Effects of pH on the degradation of phenanthrene and pyrene by Mycobacterium vanbaalenii PYR-1. Appl. Microbiol. Biotechnol. 67. https://doi.org/10.1007/s00253-004-1796-y

Kumari, S., Regar, R.K., Manickam, N., 2018. Improved polycyclic aromatic hydrocarbon degradation in a crude oil by individual and a consortium of bacteria. Bioresour. Technol. 254, 174-179. https://doi.org/10.1016/j.biortech.2018.01.075

Kuppusamy, S., Thavamani, P., Megharaj, M., Lee, Y.B., Naidu, R., 2016a. Isolation and characterization of polycyclic aromatic hydrocarbons (PAHs) degrading, $\mathrm{pH}$ tolerant, $\mathrm{N}$-fixing and $\mathrm{P}$-solubilizing novel 
bacteria from manufactured gas plant (MGP) site soils. Environ. Technol. Innov. 6, 204-219. https://doi.org/10.1016/j.eti.2016.04.006

Kuppusamy, S., Thavamani, P., Megharaj, M., Naidu, R., 2016b. Biodegradation of polycyclic aromatic hydrocarbons (PAHs) by novel bacterial consortia tolerant to diverse physical settings - Assessments in liquid- and slurry-phase systems. Int. Biodeterior. Biodegrad. 108, 149-157.

https://doi.org/10.1016/j.ibiod.2015.12.013

Lawson, C.E., Harcombe, W.R., Hatzenpichler, R., Lindemann, S.R., Löffler, F.E., O’Malley, M.A., García Martín, H., Pfleger, B.F., Raskin, L., Venturelli, O.S., Weissbrodt, D.G., Noguera, D.R., McMahon, K.D., 2019. Common principles and best practices for engineering microbiomes. Nat. Rev. Microbiol. 17, 725-741. https://doi.org/10.1038/s41579-019-0255-9

Lee, D.W., Lee, H., Lee, A.H., Kwon, B.O., Khim, J.S., Yim, U.H., Kim, B.S., Kim, J.J., 2018. Microbial community composition and PAHs removal potential of indigenous bacteria in oil contaminated sediment of Taean coast, Korea. Environ. Pollut. 234, 503-512.

https://doi.org/10.1016/j.envpol.2017.11.097

Li, X., Lin, X., Li, P., Liu, W., Wang, L., Ma, F., Chukwuka, K.S., 2009. Biodegradation of the low concentration of polycyclic aromatic hydrocarbons in soil by microbial consortium during incubation. J. Hazard. Mater. 172, 601-605. https://doi.org/10.1016/j.jhazmat.2009.07.044

Liu, N., Li, D., Li, K., Wang, L., Xu, R., Zhang, J., Yang, B., 2021. Enhanced biodegradation of chlorobenzene via combined $\mathrm{Fe}^{3+}$ and $\mathrm{Zn}^{2+}$ based on rhamnolipid solubilisation. J. Environ. Sci. 103, 108-118. https://doi.org/10.1016/j.jes.2020.10.002

Liu, S.H., Zeng, G.M., Niu, Q.Y., Liu, Y., Zhou, L., Jiang, L.H., Tan, X. fei, Xu, P., Zhang, C., Cheng, M., 2017. Bioremediation mechanisms of combined pollution of PAHs and heavy metals by bacteria and fungi: A mini review. Bioresour. Technol. 224, 25-33. https://doi.org/10.1016/j.biortech.2016.11.095

Liu, X. xin, Hu, X., Cao, Y., Pang, W. jing, Huang, J. yu, Guo, P., Huang, L., 2019. Biodegradation of phenanthrene and heavy metal removal by acid-tolerant Burkholderia fungorum FM-2. Front. Microbiol. 10, 408. https://doi.org/10.3389/fmicb.2019.00408

Lors, C., Damidot, D., Ponge, J.F., Périé, F., 2012. Comparison of a bioremediation process of PAHs in a PAH-contaminated soil at field and laboratory scales. Environ. Pollut. 165, 11-17.

https://doi.org/10.1016/j.envpol.2012.02.004

Lu, C., Hong, Y., Liu, J., Gao, Y., Ma, Z., Yang, B., Ling, W., Waigi, M.G., 2019. A PAH-degrading bacterial community enriched with contaminated agricultural soil and its utility for microbial bioremediation. Environ. Pollut. 251, 773-782. https://doi.org/10.1016/j.envpol.2019.05.044 
Lu, J.K., He, X.H., Huang, L.B., Kang, L.H., Xu, D.P., 2012. Two Burkholderia strains from nodules of Dalbergia odorifera T. Chen in Hainan Island, southern China. New For. 43, 397-409.

https://doi.org/10.1007/s11056-011-9290-8

Ma, J., Xu, L., Jia, L., 2012. Degradation of polycyclic aromatic hydrocarbons by Pseudomonas sp. JM2 isolated from active sewage sludge of chemical plant. J. Environ. Sci. (China) 24, 2141-2148.

https://doi.org/10.1016/S1001-0742(11)61064-4

Ma, M., Zheng L., Yin X F., Gao W., Han B., Li Q., Zhu A M., Chen H., 2021. Reconstruction and evaluation of oil-degrading consortia isolated from sediments of hydrothermal vents in the South Mid-Atlantic Ridge. Sci Rep. 11, 1456 (2021). https://doi.org/10.1038/s41598-021-80991-5

Meng, P., Pei, H., Hu, W., Shao, Y., Li, Z., 2014. How to increase microbial degradation in constructed wetlands: Influencing factors and improvement measures. Bioresour. Technol. 157, 316-326.

https://doi.org/10.1016/j.biortech.2014.01.095

Morya, R., Salvachúa, D., Thakur, I.S., 2020. Burkholderia: An untapped but promising bacterial genus for the conversion of aromatic compounds. Trends Biotechnol. 38, 963-975.

https://doi.org/10.1016/j.tibtech.2020.02.008

Nie, M., Yin, X., Ren, C., Wang, Y., Xu, F., Shen, Q., 2010. Novel rhamnolipid biosurfactants produced by a polycyclic aromatic hydrocarbon-degrading bacterium Pseudomonas aeruginosa strain NY3. Biotechnol. Adv. 28, 635-643. https://doi.org/10.1016/j.biotechadv.2010.05.013

Nzila, A., 2018. Biodegradation of high-molecular-weight polycyclic aromatic hydrocarbons under anaerobic conditions: Overview of studies, proposed pathways and future perspectives. Environ. Pollut. 239, 788-802. https://doi.org/10.1016/j.envpol.2018.04.074

Oberoi, A.S., Philip, L., Bhallamudi, S.M., 2015. Biodegradation of various aromatic compounds by enriched bacterial cultures: Part A-Monocyclic and polycyclic aromatic hydrocarbons. Appl. Biochem. Biotechnol. 176, 1870-1888. https://doi.org/10.1007/s12010-015-1684-1

Patel, A.B., Mahala, K., Jain, K., Madamwar, D., 2018. Development of mixed bacterial cultures DAK11 capable for degrading mixture of polycyclic aromatic hydrocarbons (PAHs). Bioresour. Technol. 253, 288-296. https://doi.org/10.1016/j.biortech.2018.01.049

Patel, A.B., Singh, S., Patel, A., Jain, K., Amin, S., Madamwar, D., 2019. Synergistic biodegradation of phenanthrene and fluoranthene by mixed bacterial cultures. Bioresour. Technol. 284, 115-120. https://doi.org/10.1016/j.biortech.2019.03.097

Patel, V., Jain, S., Madamwar, D., 2012. Naphthalene degradation by bacterial consortium (DV-AL) developed from Alang-Sosiya ship breaking yard, Gujarat, India. Bioresour. Technol. 107, 122-130. https://doi.org/10.1016/j.biortech.2011.12.056 
Pradeep, S., Sarath Josh, M.K., Binod, P., Sudha Devi, R., Balachandran, S., Anderson, R.C., Benjamin, S., 2015. Achromobacter denitrificans strain SP1 efficiently remediates di(2-ethylhexyl)phthalate. Ecotoxicol. Environ. Saf. 112, 114-121. https://doi.org/10.1016/j.ecoenv.2014.10.035

Qin, Z., Zhao, Z., Xia, L., Adam, A., Li, Y., Chen, D., Mela, S.M., Li, H., 2019. The dissipation and risk alleviation mechanism of PAHs and nitrogen in constructed wetlands: The role of submerged macrophytes and their biofilms-leaves. Environ. Int. 131, 104940.

https://doi.org/10.1016/j.envint.2019.104940

Quast, C., Pruesse, E., Yilmaz, P., Gerken, J., Schweer, T., Yarza, P., Peplies, J., Glöckner, F.O., 2012. The SILVA ribosomal RNA gene database project: improved data processing and web-based tools. Nucleic Acids Res. 41, D590-D596. https://doi.org/10.1093/nar/gks1219

Rabodonirina, S., Rasolomampianina, R., Krier, F., Drider, D., Merhaby, D., Net, S., Ouddane, B., 2019. Degradation of fluorene and phenanthrene in PAHs-contaminated soil using Pseudomonas and Bacillus strains isolated from oil spill sites. J. Environ. Manage. 232, 1-7.

https://doi.org/10.1016/j.jenvman.2018.11.005

Sei, K., Inoue, D., Wada, K., Mori, K., Ike, M., Kohno, T., Fujita, M., 2004. Monitoring behaviour of catabolic genes and change of microbial community structures in seawater microcosms during aromatic compound degradation. Water Res. 38, 4405-4414. https://doi.org/10.1016/j.watres.2004.08.028

Sharma, A., Singh, S.B., Sharma, R., Chaudhary, P., Pandey, A.K., Ansari, R., Vasudevan, V., Arora, A., Singh, S., Saha, S., Nain, L., 2016. Enhanced biodegradation of PAHs by microbial consortium with different amendment and their fate in in-situ condition. J. Environ. Manage. 181, 728-736.

https://doi.org/10.1016/j.jenvman.2016.08.024

Sihag Pathak, H., and Jaroli, D., S., 2014. Factors affecting the rate of biodegradation of polyaromatic hydrocarbons. Int. J. Pure Appl. Biosci. 2, 185-202.

Somtrakoon, K., Suanjit, S., Pokethitiyook, P., Kruatrachue, M., Lee, H., Upatham, S., 2008. Enhanced biodegradation of anthracene in acidic soil by inoculated Burkholderia sp. VUN10013. Curr. Microbiol. 57, 102-106. https://doi.org/10.1007/s00284-008-9157-1

Tao, X.Q., Lu, G.N., Dang, Z., Yang, C., Yi, X.Y., 2007. A phenanthrene-degrading strain Sphingomonas sp. GY2B isolated from contaminated soils. Process Biochem. 42.

https://doi.org/10.1016/j.procbio.2006.09.018

Vidonish, J.E., Zygourakis, K., Masiello, C.A., Sabadell, G., Alvarez, P.J.J., 2016. Thermal treatment of hydrocarbon-impacted soils: A review of technology innovation for sustainable remediation. Engineering 2, 426-437. https://doi.org/10.1016/J.ENG.2016.04.005 
Wanapaisan, P., Laothamteep, N., Vejarano, F., Chakraborty, J., Shintani, M., Muangchinda, C., Morita, T., Suzuki-Minakuchi, C., Inoue, K., Nojiri, H., Pinyakong, O., 2018. Synergistic degradation of pyrene by five culturable bacteria in a mangrove sediment-derived bacterial consortium. J. Hazard. Mater. 342, 561570. https://doi.org/10.1016/j.jhazmat.2017.08.062

Wang, Q., Hou, J., Yuan, J., Wu, Y., Liu, W., Luo, Y., Christie, P., 2020. Evaluation of fatty acid derivatives in the remediation of aged $\mathrm{PAH}$-contaminated soil and microbial community and degradation gene response. Chemosphere 248, 125983. https://doi.org/10.1016/j.chemosphere.2020.125983

Wen, J., Gao, D., Zhang, B., Liang, H., 2011. Co-metabolic degradation of pyrene by indigenous white-rot fungus Pseudotrametes gibbosa from the northeast China. Int. Biodeterior. Biodegrad. 65, 600-604. https://doi.org/10.1016/j.ibiod.2011.03.003

Wong, J.W.C., Lai, K.M., Wan, C.K., Ma, K.K., Fang, M., 2002. Isolation and optimization of PAHdegradative bacteria from contaminated soil for PAHs bioremediation. Water. Air. Soil Pollut. https://doi.org/10.1023/A:1015883924901

Wu, M., Chen, L., Tian, Y., Ding, Y., Dick, W.A., 2013. Degradation of polycyclic aromatic hydrocarbons by microbial consortia enriched from three soils using two different culture media. Environ. Pollut. 178, 152158. https://doi.org/10.1016/j.envpol.2013.03.004

Xiao, M., Yin, X., Gai, H., Ma, H., Qi, Y., Li, K., Hua, X., Sun, M., Song, H., 2019. Effect of hydroxypropyl-Bcyclodextrin on the cometabolism of phenol and phenanthrene by a novel Chryseobacterium sp. Bioresour. Technol. 273, 56-62. https://doi.org/10.1016/j.biortech.2018.10.087

Yu, L., Duan, L., Naidu, R., Semple, K.T., 2018. Abiotic factors controlling bioavailability and bioaccessibility of polycyclic aromatic hydrocarbons in soil: Putting together a bigger picture. Sci. Total Environ. 613-614, 1140-1153. https://doi.org/10.1016/j.scitotenv.2017.09.025

Yuan, J., 2015. The diversity of PAH-degrading bacteria in a deep-sea water column above the Southwest Indian Ridge. Front. Microbiol. 6. https://doi.org/10.3389/fmicb.2015.00853

Yuan, S.Y., Shiung, L.C., Chang, B. V., 2002. Biodegradation of polycyclic aromatic hydrocarbons by inoculated microorganisms in soil. Bull. Environ. Contam. Toxicol. 69, 66-73.

https://doi.org/10.1007/s00128-002-0011-z

Zang, T., Wu, H., Yan, B., Zhang, Y., Wei, C., 2020. Enhancement of PAHs biodegradation in biosurfactant/phenol system by increasing the bioavailability of PAHs. Chemosphere 266, 128941. https://doi.org/10.1016/j.chemosphere.2020.128941

\section{Figures}




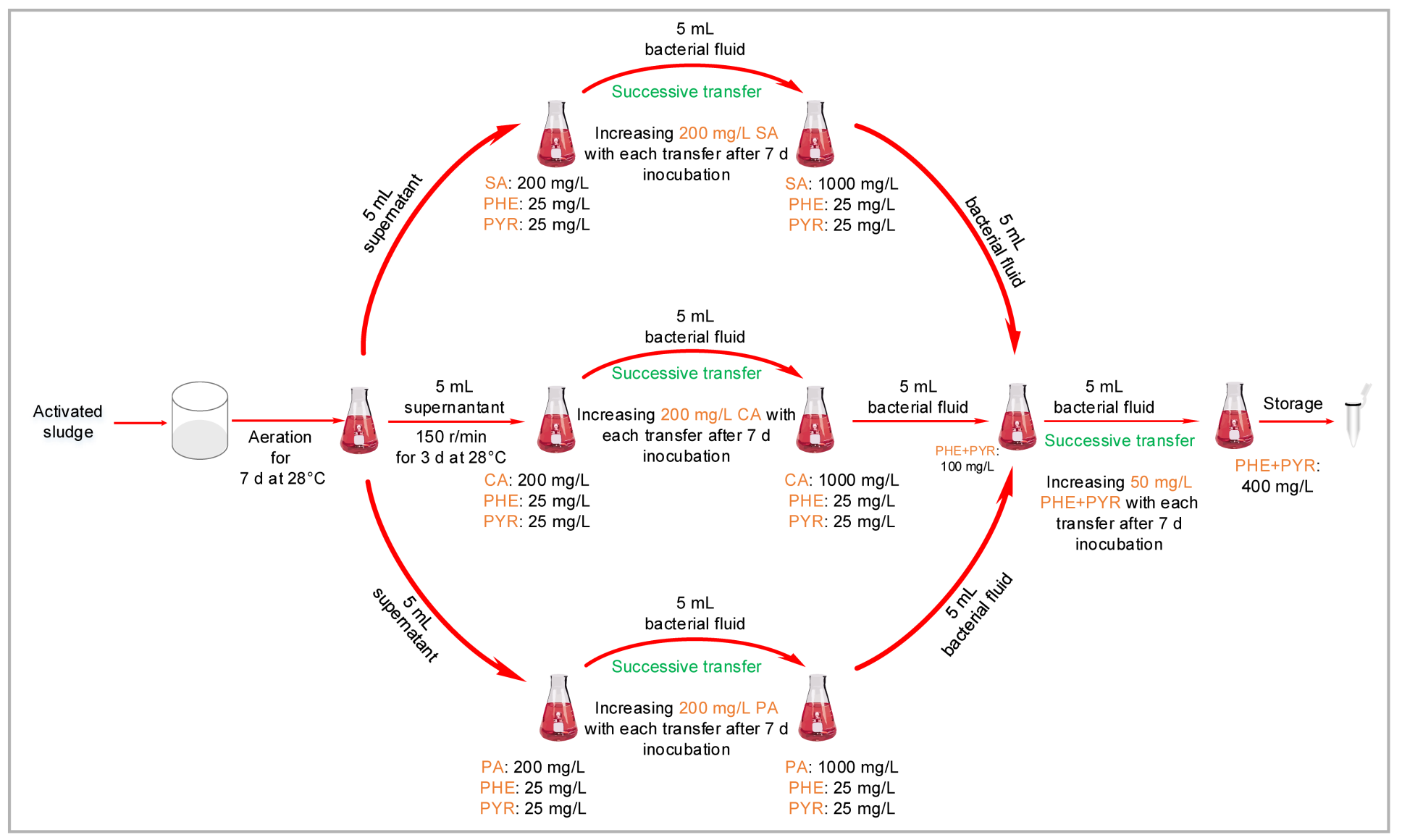

Figure 1

Schematic illustration of the multisubstrate enrichment process. $\mathrm{PHE}=$ phenanthrene; $\mathrm{PYR}=$ pyrene; $\mathrm{CA}=$ catechol; SA = salicylic acid; $\mathrm{PA}$ = phthalic acid.

Figure 2

Bacterial composition at phylum level during the multisubstrate enrichment process. $A S=$ activated sludge; $\mathrm{CA}$ = catechol; $\mathrm{SA}=$ salicylic acid; $\mathrm{PA}=$ phthalic acid; $\mathrm{MBF}$ is the consortium after the multisubstrate enrichment. 


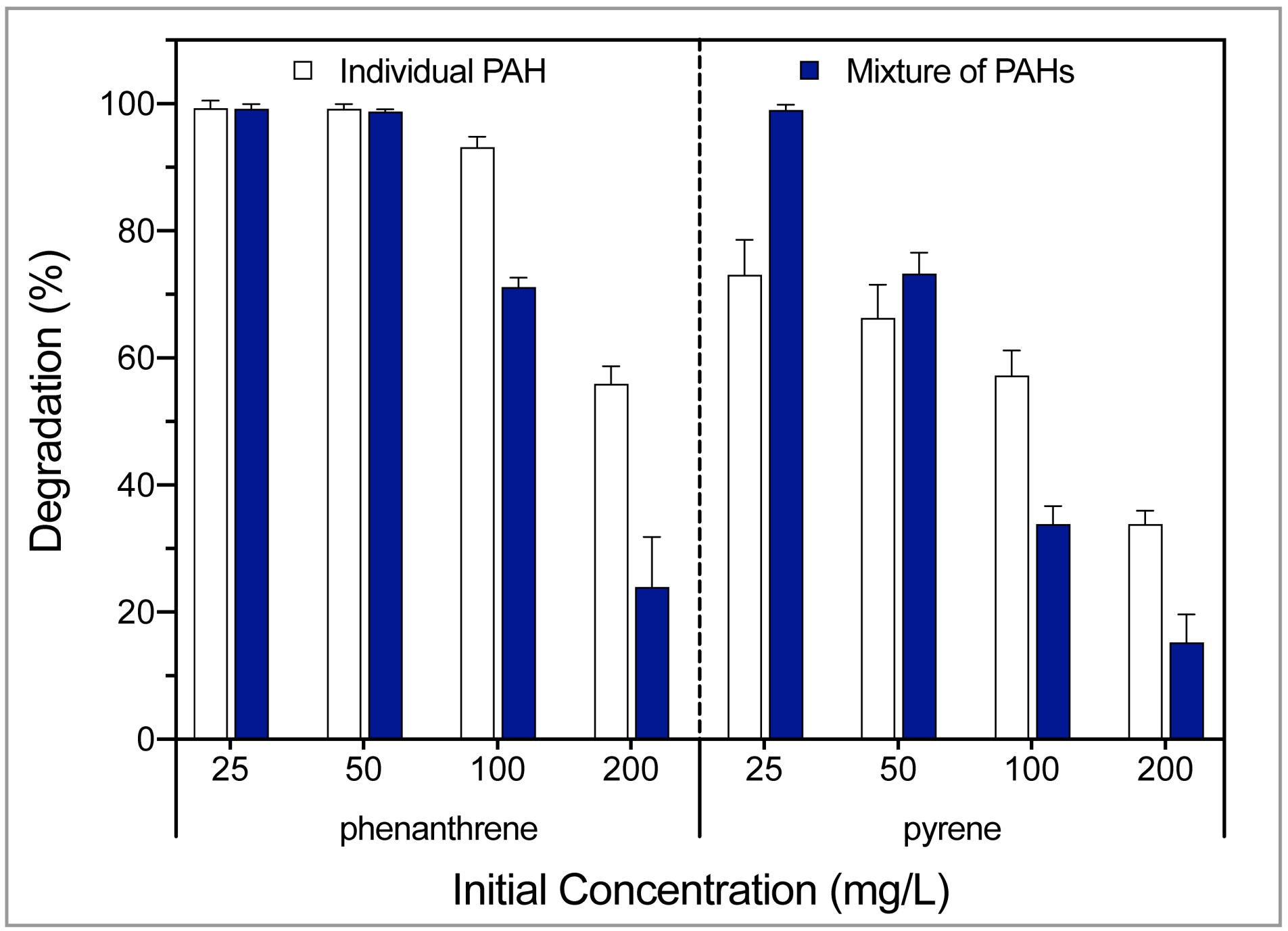

Figure 3

Biodegradation of PAH (phenanthrene, and pyrene) when they were provided as an individual and as a mixture of PAHs under initial concentrations $(25 \mathrm{mg} / \mathrm{L}, 50 \mathrm{mg} / \mathrm{L}, 100 \mathrm{mg} / \mathrm{L}$, and $200 \mathrm{mg} / \mathrm{L}$ ) by consortium MBF after incubation of 5 days at $28^{\circ} \mathrm{C}$ under shaking condition (150 rpm). The degradation was calculated in percentage, and error bars represented the standard deviation of triplicate independent measurements.

\section{Figure 4}

Biodegradation of phenanthrene and pyrene as a mixture by consortium MBF after incubation of 1,3 , and 5 days under different temperatures (a), $\mathrm{pH}$ values (b), and salinities (c). The initial concentration of phenanthrene and pyrene was $50 \mathrm{mg} / \mathrm{L}$. The different letters represented significant differences at Pvalues $\leq 0.05$ based on one-way ANOVA analyses (Regular letter and Italic letter correspond to phenanthrene and pyrene biodegradation, respectively). 


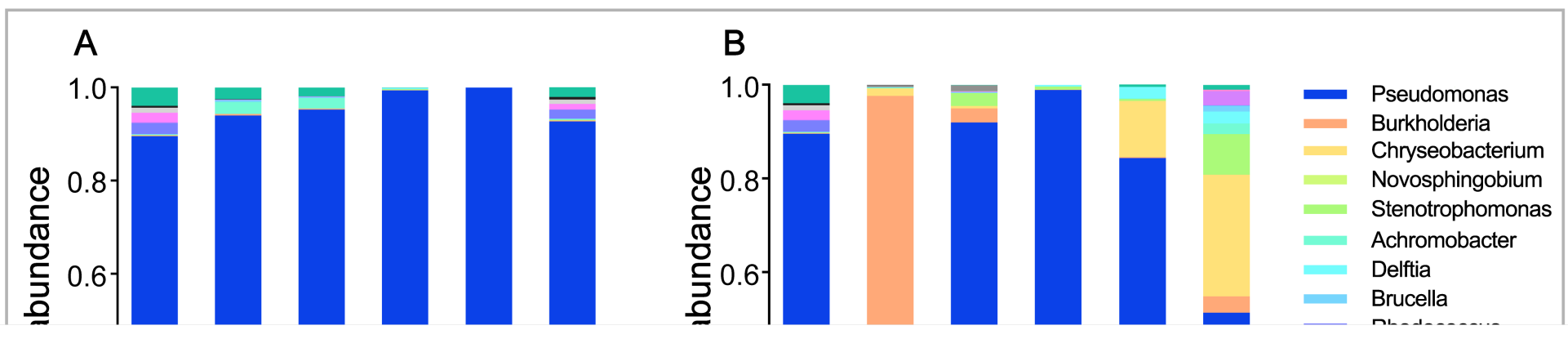

\section{Figure 5}

Bacterial compositions at genus level under different temperatures (a), pH values (b), salinities (c), and principal coordinates analysis (PCoA) based on weighted UniFrac distance (d).

\section{Figure 6}

Biodegradation of a mixture of PAHs (phenanthrene and pyrene) in the presence of pathway intermediate metabolites by consortium MBF after incubation of 1,3 , and 5 days at $28^{\circ} \mathrm{C}$ under shaking condition (150 rpm). The degradation was calculated in percentage, and error bars represented the standard deviation of triplicate independent measurements. $\mathrm{CK}=$ control check; $\mathrm{CA}=$ catechol; $\mathrm{SA}=$ salicylic acid; PA = phthalic acid. 


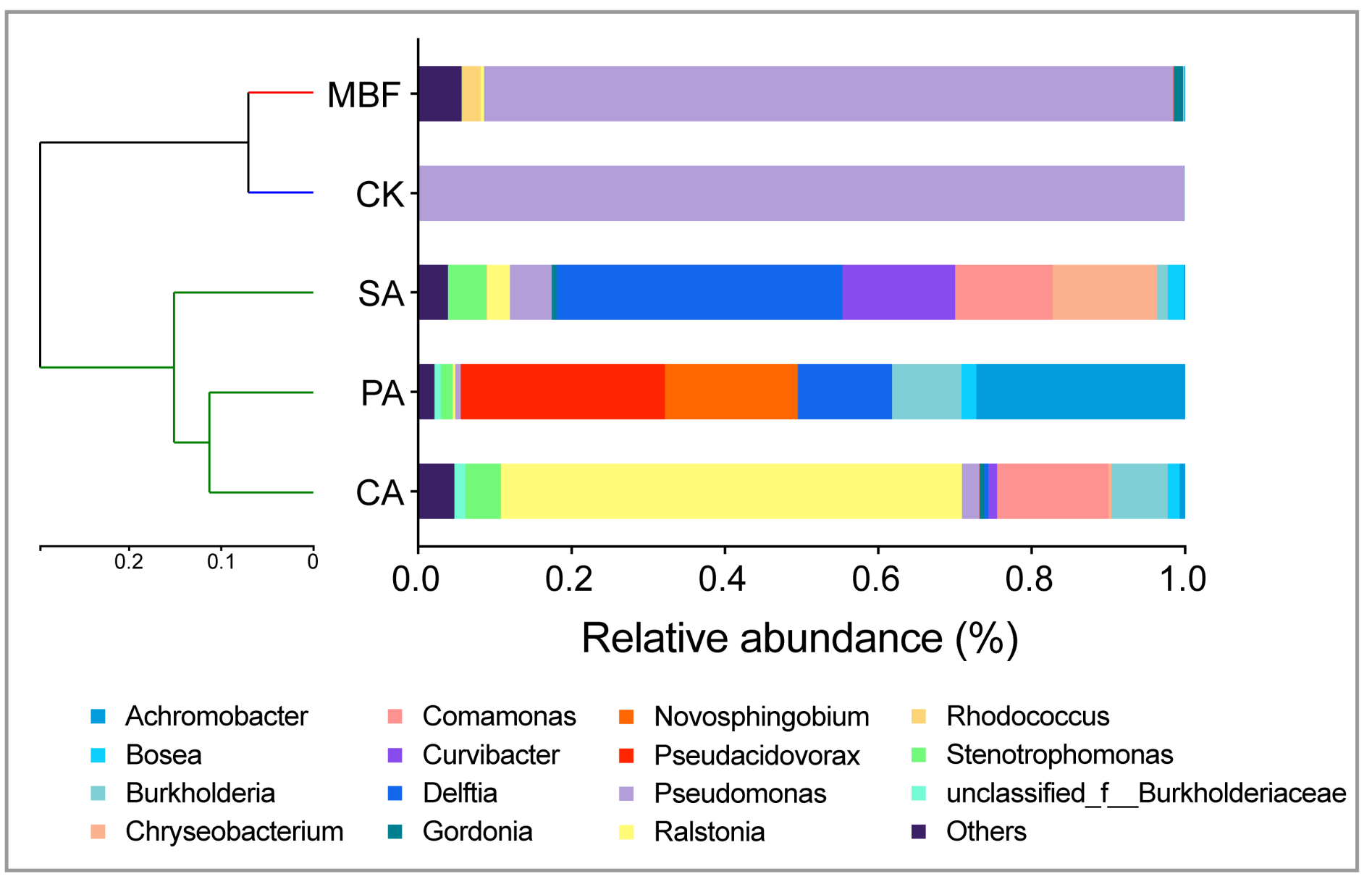

\section{Figure 7}

Bacterial compositions at genus level after biodegradation of phenanthrene and pyrene as a mixture in the presence of pathway intermediate metabolites. $\mathrm{CK}=$ control check; $\mathrm{CA}=$ catechol; $\mathrm{SA}=$ salicylic acid; PA = phthalic acid.

\section{Supplementary Files}

This is a list of supplementary files associated with this preprint. Click to download.

- Appendices.docx 